\title{
Presença de anticorpos da classe IgM de Leptospira interrogans em animais silvestres do Estado do Tocantins, 2002
}

\author{
Presence of IgM antibodies for Leptospira interrogans in wild animals from \\ Tocantins State, 2002
}

\author{
Milton Formiga de Souza Júnior ${ }^{1}$, Zélia Inês Portela Lobato ${ }^{1}$, Francisco Carlos Faria Lobato ${ }^{1}$, \\ Élvio Carlos Moreira ${ }^{1}$, Rogério Rodrigues de Oliveira ${ }^{1}$, Geysa Goulart Leite ${ }^{2}$, \\ Theonys Diógenes Freitas ${ }^{1}$ e Ronnie Antunes de Assis ${ }^{1}$
}

\begin{abstract}
RESUMO
Quatrocentos e vinte e sete amostras de soro provenientes de animais silvestres foram testadas frente a 18 sorovariedades de Leptospira interrogans. De 286 amostras de Cebus apella, 46 (16,1\%) foram positivas para as sorovariedades pomona, brasiliensis, mini, swajizak, grippothyphosa, sarmin, fluminense, autumnalis, hebdomadis, guaratuba, javanica $e$ icterohaemorhagiae. Das 82 de Alouatta caraya, 2 (2,4\%) foram positivas para as sorovariedades mangus e fluminense. Das 31 de Nasua nasua, 4 (12,9\%) foram positivas para as sorovariedades fluminense $e$ javanica. Das 10 amostras de Cerdocyon thous, 2 (20\%) foram positivas para as sorovariedades fluminense e brasiliensis. Sete de Dasyprocta sp, 6 de Tamandua tetradactila $e 5$ de Euphractus sexcintus não apresentaram reatividade.
\end{abstract}

Palavras-chaves: Leptospirose. Leptospira interrogans. Animais silvestres. IgM.

\begin{abstract}
Four hundred and twenty-seven serum samples of wild animals were tested against 18 serovars of Leptospira interrogans. Of 286 samples of Cebus apella, 46 (16.1\%) were positive for the serovars pomona, brasiliensis, mini, swajizak, grippotyphosa, sarmin, fluminense, autumnalis, hebdomadis, guaratuba, javanica and icterohaemorrhagiae. Of 82 samples of Alouatta caraya, 2 (2.4\%) were positive for the serovars mangus and fluminense. Of 31 samples of Nasua nasua, 4 (12.9\%) were positive for the serovars fluminense and javanica, and of 10 samples of Cerdocyon thous, $2(20 \%)$ were positive for the serovars fluminense and brasiliensis. Seven samples of Dasyprocta sp, 6 of Tamandua tetradactyla and 5 of Euphractus sexcintus did not present reactivity.
\end{abstract}

Key-words: Leptospirosis. Leptospira interrogans. Wild animals. IgM.

A leptospirose é uma doença de importância mundial com implicações na saúde pública e animal, capaz de promover quadros infecciosos e grandes perdas econômicas. Os roedores constituem um dos principais reservatórios das espiroquetas, transmitindo a doença aos humanos e diferentes espécies animais ${ }^{8}$.

Algumas espécies animais são reservatórios de importantes sorovariedades de Leptospira interrogans. Os mais freqüentes em bovinos são hardjo, wolffi, icterohaemorrhagiae, pomona, grippotyphosa, copenhageni e bratislava; em suínos bratislava, icterohaemorrhagiae, pomona, hardjo e grippotyphosa; em cães copenhageni, canicola, bratislava, tarassovi, australis, icterohaemorrhagiae e pyrogenes. Entre as espécies de roedores, Rattus spp, é considerada susceptível a sorovariedade icterohaemorrhagiae, e camundongos a sorovariedade ballum?

Devido à existência de poucos relatos sobre leptospirose em animais silvestres, este trabalho teve por objetivo pesquisar anticorpos da classe IgM contra Leptospira interrogans em sete espécies de animais silvestres resgatados durante 0 enchimento

1. Departamento de Medicina Veterinária Preventiva e Epidemiologia da Escola de Veterinária da Universidade Federal de Minas Gerais, Belo Horizonte, MG. 2. Médica Veterinária, Palmas, TO.

Endereço para correspondência: Dr. Francisco Carlos Faria Lobato. Dept ${ }^{\circ}$ de Medicina Veterinária Preventiva e Epidemiologia/EV/UFMG. Av. Antônio Carlos 6627, Caixa Postal 567, Pampulha, 30123-970 Belo Horizonte, MG.

Tel: 5531 3499-2029; Fax: 5531 3499-2080

e-mail: flobato@vet.ufmg.br

Recebido para publicação em 06/06/2005

Aceito em: 27/03/2006 
do lago da Usina Hidrelétrica Luís Eduardo Magalhães localizada entre os municípios de Lajeado e Ipueiras, no Estado do Tocantins, Brasil.

Amostras de soro e espécies animais estudadas. 0 estudo foi realizado em 427 amostras de soro (uma/animal) das espécies Cebus apella (macaco prego, $\mathrm{n}=286$ ), Alouatta caraya (macaco guariba, $\mathrm{n}=82$ ), Nasua nasua (quatis, $\mathrm{n}=31$ ), Cerdocyon thous (raposas cinzentas, $\mathrm{n}=10$ ), Dasyprocta $s p$ (cotias, $\mathrm{n}=7$ ), Tamandua tetradactila (tamanduá mirim, n=6) e Euphractus sexcintus (tatu peba, $\mathrm{n}=5$ ).

Captura dos animais e obtenção das amostras de soro. os animais ilhados durante o enchimento do lago foram resgatados para salvamento. 0 resgate foi executado com equipamentos apropriados para a captura e contenção de animais. Após captura e contenção física, os animais foram acondicionados em caixas de madeira específicas para a contenção de mamíferos, e em seguida, encaminhados às bases de triagens, localizadas em pontos estratégicos ao longo do rio Tocantins. Nas bases de triagem, após um período de 15-30 minutos de descanso, procedeu-se administração de sedativos pertencentes às classes das feniciclidinas (Tiletamina) e benzodiazepinas (Zolazepam) em partes iguais, na quantidade de $3,6 \mathrm{mg} / \mathrm{kg}$ de peso vivo (p.v.) por via intramuscular (IM) na espécie $A$. caraya e $4,4 \mathrm{mg} / \mathrm{kg}$ de p.v., pela via IM. para a espécie C. apella. Para as espécies, $N$. nasua, C. thous, Dasyprocta $s p$, T. tetradactila e E. sexcintus, foi usada uma mistura de xilazina com ketamina na dosagem de 1 e $7 \mathrm{mg} / \mathrm{kg}$ de p.v., respectivamente. Após sedação, realizou-se colheita de sangue em tubos Vacuntainer ${ }^{\circledR}$ para as avaliações sorológicas, as espécies $C$. apella e $A$. caraya através das veias inguinais e as demais, pelas veias radiais e cefálica. Após colheita, procediase imediatamente avaliação médico-veterinária dos animais e em seguida, soltura dos mesmos em fazendas previamente cadastradas pelos Programas Básicos Ambientais, feitos desde a implantação da usina Hidrelétrica ${ }^{56}$. Os tubos foram mantidos inclinados por 30 minutos à temperatura ambiente $\mathrm{e}$ posteriormente centrifugados por 10 minutos a $3000 \mathrm{x} \mathrm{g}$.

Análise laboratorial. os soros obtidos foram remetidos sob refrigeração ao Laboratório de Leptospirose da Escola de Veterinária da UFMG e mantidos a $-20^{\circ} \mathrm{C}$ até a realização dos ensaios. Os mesmos foram examinados para a presença de anticorpos da classe IgM de $L$. interrogans pela técnica de aglutinação microscópica ${ }^{1}$ frente as seguintes sorovariedades empregadas como antígenos: wolffi, mini, cuíca, grippotyphosa, sarmin, manguns, fluminense, australis, hebdomadis, guaratuba, mini, autumnalis, swajizak, javanica, ballum, icterohaemorhagiae, pomona e brasiliensis. Durante o período do experimento, realizou-se monitoramento das espécies nestes ambientes, avaliando-se principalmente o processo de adaptação das mesmas na nova área, diferente daquelas onde viviam.

Das 286 amostras de Cebus apella (macaco prego), $46(16,1 \%)$ foram positivas para as sorovariedades pomona, brasiliensis, mini, swajizak, grippothyphosa, sarmin, fluminense, autumnalis, hebdomadis, guaratuba, javanica $e$ icterohaemorhagiae; das 82 amostras de A. caraya (macaco guariba), 2 (2,4\%) foram positivas para os sorovares mangus e fluminense; das 31 amostras de $N$. nasua (quatis), $4(12,9 \%)$ foram positivas para as sorovariedades fluminense e javanica e das 10 amostras de $C$. thous (raposas cinzentas), $2(20 \%)$ foram positivas para as sorovariedades fluminense e brasiliensis. As espécies Dasyprocta sp (cotias) com 7 amostras, T. tetradactila (tamanduá mirim) com 6 amostras e $E$. sexcintus (tatu peba) com 5 amostras, não apresentaram reatividade para nenhuma das 18 sorovariedades utilizadas. Os títulos dos diferentes soros testados para as distintas sorovariedades de $L$. interrogans, variaram de 1:100 a 1:1600.

Costa cols ${ }^{3}$ realizaram pesquisas sorológicas em animais silvestres localizados nos estados do Pará e Amapá, e constataram que nas espécies Cebus sp, Saimiri sp e Saguinus midas, foram detectadas aglutininas para as sorovariedades tarassovi, grippotyphosa e djasiman. Em um estudo feito em várias regiões do Estado da Bahia, Dória cols ${ }^{4}$ observaram que de 16 primatas da espécie Callithrix penicillata, 3 (18,7\%) foram positivas para as sorovariedades australis e pomona. Corrêa cols ${ }^{2}$ observaram que dos 20 Alouatta fusca, 7 (35\%) apresentaram positividade para os sorovares javanica, djasiman e ballum. Portanto, a constatação da presença de aglutininas anti-L. interrogans nas espécies deste estudo, parece ser a primeira no Brasil.

Neste estudo, à semelhança dos previamente relatados, pesquisando aglutininas anti- $L$. interrogans em diferentes espécies de animais silvestres, verificou-se que as sete espécies estudadas, apresentam distintas sorovariedades deste microrganismo. Tal fato é de fundamental importância uma vez que, populações humanas e animais que porventura estão ou entrem em contato com esses animais, estão vulneráveis à infecção por L. interrogans.

\section{AGRADECIMENTOS}

Cordialmente agradecemos à Empresa INVESTCO S/A pela autorização das colheitas de sangue das espécies estudadas; ao CEULP/ULBRA pelo apoio técnico, aos coordenadores técnicos do Projeto Resgate de Fauna (PRF); Dr. Fernando Martins Costa, Dra. Maria Amélia Fernandino Maciel pelas informações e críticas, à Bióloga Dra. Ana Fátima pela cooperação e ajuda nas colheitas, e a todos os demais integrantes do PRF que de alguma forma contribuíram para $o$ início e término deste trabalho.

\section{REFERÊNCIAS BIBLIOGRÁFICAS}

1. Cole JR, Sulzer CR, Pursll AR. Improved microtecnic for leptospiral microcopic aglutination test. Applied Microbiology 25:976-986, 1973.

2. Corrêa MOA, Hyakutake S, Natale V, Galvão PAA, Aguiar HA. Estudos sobre a Leptospira wolffi em São Paulo. Revista do Instituto Adolfo Lutz 25/27: 11-25, 1965/1967.

3. Costa CA, Rezende M, Lins P. Leptospiroses no Estado do Pará e Território Federal do Amapá. Revista do Instituto Adolfo Lutz 29/30:1-4, 1969/1970.

4. Dória JD, Silva AG, Costa AR. Leptospirose. Presença de aglutininas antileptospira no soro de saguis (Callithrix penicillata) no Estado da Bahia. (nota prévia). Boletim do Instituto de Biologia da Bahia 13:148-149, 1974. 
5. Investco-Themag. Plano Básico Ambiental. Pesquisa e manejo de fauna e flora na usina Hidrelétrica Lajeado, 1996.

6. Investco-Ecopalmas. Plano de Trabalho para a pesquisa e Manejo de Fauna Silvestre na Usina Hidroeléttrica Luís Eduardo Magalhães, 1999.
7. Oliveira SJ, Pires Neto JAS. Aspectos etiológicos e de diagnóstico nas lesptospiroses. Revista do Conselho Federal de Medicina Veterinária 10:36-46, 2004.

8. Torten M. Leptospirosis. In: Steele JH (ed) CRC Handbrook Series in Zoonoses. Editora CRC Press Inc, Boca Ration, Florida p.367-382, 1979. 